Journal of Science
http://dergipark.gov.tr/gujs

\title{
Polydopamine Mediated Growth of Ag Nanostructures on ZnO Thin Films for Catalytic Degradation of Organic Dyes
}

\author{
Mehmet KURU ${ }^{1, *}$ (D) Sami PEKDEMIR ${ }^{2,3}$ \\ ${ }^{I}$ Department of Metallurgy and Materials Engineering Ondokuz Mayls University, Samsun,55200, TURKEY. \\ ${ }^{2}$ Department of Materials Science and Engineering, Erciyes University, Kayseri, 38039, TURKEY. \\ ${ }^{3}$ ERNAM- Erciyes University Nanotechnology Application and Research Center, Kayseri, 38039, TURKEY.
}

\section{Highlights}

- $\mathrm{ZnO}$ thin films were fabricated by RF magnetron sputtering technique.

- The growth of Ag NSs with polydopamine on $\mathrm{ZnO}$ thin film surface.

- The catalytic activity of the multi-functional films.

- Metal oxide films with plasmonic structures for efficient degradation of organic dyes.

\begin{tabular}{l} 
Article Info \\
\hline Received: $13 / 11 / 2019$ \\
Accepted: $02 / 06 / 2020$ \\
Keywords \\
\hline ZnO thin film \\
Ag nanostructures \\
Polydopamine \\
Catalytic activity
\end{tabular}

\begin{abstract}
In this study, multi-functional films were produced by the solution-phase growth of plasmonic Ag nanostructures (NSs) on $\mathrm{ZnO}$ fabricated by RF magnetron sputtering technique. The Ag NSs was grown on $\mathrm{ZnO}$ coated surface by functionalizing the thin film with mussel-inspired polydopamine. The structural analysis was performed by Grazing Incident X-ray diffraction (GIXRD) and Fouirer Transform Infrared Spectrometer (FTIR) technique in order to observe the effect of the Ag NSs deposition times. The effect of growth conditions on the structure and size of Ag NSs was investigated by Field Emission Scanning Electron Microscope (FESEM) imaging technique. The chemical compositions of as-deposited and $\mathrm{Ag}$ decorated $\mathrm{ZnO}$ films confirms using Energy-dispersive X-ray spectroscopy (EDX) analysis. The catalytic performance of the multi-functional films was investigated by the degradation of organic dyes (methyl orange (MO) and rhodamine $\mathrm{B}(\mathrm{RhB}))$. The catalytic activity of $\mathrm{Ag}$ on the is examined in details where it is found that maximum catalytic performance was observed within first $15 \mathrm{~min}$ for the $\mathrm{ZnO}$ thin films that were decorated with $\mathrm{Ag}$ NSs for $24 \mathrm{~h}$. The rate constant for the degradation reaction was $33.8 \times 10^{-3} \mathrm{~min}^{-1}$ and $43.2 \times 10^{-3} \mathrm{~min}^{-1}$ for $\mathrm{MO}$ and $\mathrm{RhB}$, respectively. These results show the promise of integrating metal oxide films with plasmonic structures for efficient degradation of organic dyes.
\end{abstract}

\section{INTRODUCTION}

Organic compounds used as textile dyes, paints, pesticides, phenols and solvents have been widely used in industrial applications and daily life since the beginning of the $21^{\text {th }}$ century. Uncontrolled release of these substances into the environment by wastewater containing organic and inorganic compounds that pollute water resources, and damage soil, plants, animals and human health [1,2]. The textile industry, which is one of the most used areas of dyestuff organic compounds, generates a large amount of wastewater with high concentrations of chemicals, and these wastes are the main causes of water pollution. Also, the wastewater produced by the textile dye industry is one of the main problems of environmental pollution as it contains aromatic amino compounds with high toxicity [3]. The complex aromatic structure of these compounds increases their resistance to temperature, chemicals, light, and other environmental factors, making them difficult to deteriorate in nature and prevents their effective purification by conventional purification methods [4].

The large reduction of water resources in the world threatens ecological life seriously. This threat has resulted in strong motivation for development of new technologies for the removal of organic pollutants from the aqueous environment. Conventionally, chemical, physical and biological methods are used for 
cleaning textile dyes in wastewater. These methods cannot separate substances due to the complex and stable structures of organic dyestuffs. Therefore, in recent years, the need for innovative treatment methods is inevitable [5]. Efficient treatment of organic pollutants by environmentally friendly photocatalysis method is noteworthy [6]. This method has considerable advantages over conventional methods due to its low energy consumption and easy reaction conditions [7]. In the photocatalysis method, organic pollutants are effectively removed by benefiting from photocatalytic properties of various metal oxide semiconductors under UV light. $\mathrm{ZnO}$ is one of the most researched metal oxides due to its large energy bandgap (3.36eV), high binding energy $(60 \mathrm{meV})$, inexpensive, anti-bacterial and environmentally friendly $[8,9]$.

There are various surface modification studies to increase the photocatalytic activity of $\mathrm{ZnO}$ and other metal oxides [10]. These modifications are important because they facilitate reactions on the surface of the catalyst and broaden the absorption spectrum [11]. Modifying the surface structure of $\mathrm{ZnO}$ with metals such as Pt [12,13], Ag [14], Au [15] is the most effective way to accelerate the separation of the carrier charge from the surface and increase the catalytic efficiency.

In recent years, metallic NSs have increased significantly in their use in heterogeneous catalysis applications due to their superior catalytic properties [16]. These NSs are highly effective in reducing organic contaminants in the presence of reducing agents [17]. Like the photocatalytic mechanism, metal nanoparticles with electron relay effect can break down organic dyes without the need for any light source in the presence of $\mathrm{NaBH}_{4}$ in the environment. The degradation of dyestuffs with catalyst is kinetically challenging but thermodynamically favorable. The NSs overcome the kinetic barrier for the degradation of the dyestuffs by creating alternative pathways that reduce the activation energy. Thus, very fast reactions can occur according to the photocatalytic degradation [18]. In the literature, it is possible to see a range of different studies for photocatalytic degradation, and the breakdown of dyestuffs using electron transfer are gaining increasing attention [19]. The challenges in the reusability and agglomeration of powder catalysts motivate research for catalytically active solid substrates [20]. The synergistic exploitation of metal oxide thin films decorated with metallic nanostructures show great potential for the degradation of organic dyes without any light source in the presence of $\mathrm{NaBH}_{4}$ in the environment.

In this study, a multi-functional surface was produced by decorating plasmonic Ag NSs onto ZnO films fabricated by RF magnetron sputtering technique on $\mathrm{Si}$ (100) substrate. Various methods such as RF/DC magnetron sputtering, chemical vapor deposition (CVD), pulsed laser deposition (PLD), organic vapor phase epitaxy (MOVPE), molecular beam epitaxy (MBE), and sol-gel are used in the production of $\mathrm{ZnO}$ thin films [21,22]. Magnetron sputtering, in particularly, enables tuning of the chemical composition and practically rates of film deposition. Furthermore, since the magnetron sputtering technique is carried out under high vacuum, it provides the possibility of producing a high purity, homogeneous and high-quality thin film. Surface growth of Ag NSs was realized by functionalization of the $\mathrm{ZnO}$ thin film with musselinspired polydopamine [23]. The solution-phase deposition of polydopamine enables versatile functionalization of the surface and provides chemical groups that are necessary for the reduction of $\mathrm{Ag}$ ions. The effect of growth conditions on the size and structure of Ag NSs was investigated by FESEM imaging technique. The produced multi-functional surfaces showed high levels of catalytic activity. The catalytic performance of the multi-functional films was investigated by the degradation of MO and RhB.

\section{MATERIAL AND METHOD}

\subsection{ZnO Thin Film Growth}

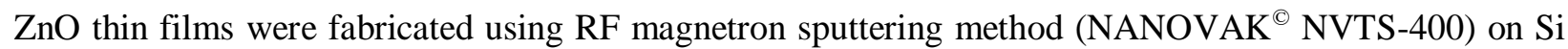
(100) substrate. $\mathrm{ZnO}$ target of $99.999 \%$ purity and argon gas of the same purity were used in the production of $\mathrm{ZnO}$ films. Before the deposition, $\mathrm{Si}$ (100) substrates were cleaned with ultrasonic cleaner using acetone, ethanol and dried by nitrogen gas blowing, respectively. The chamber was purged down to $2 \times 10^{-6}$ Torr base pressure prior to the deposition. Thin films were fabricated under $4.5 \mathrm{mTorr}$ pressure, $15 \mathrm{sccm}$ argon flow rate, $75 \mathrm{~W}$ RF power and room temperature conditions. The deposition rate of $\mathrm{ZnO}$ thin films with a thickness of $250 \mathrm{~nm}$ was $0.4 \AA / \mathrm{s}$. The thickness of the films was measured by the QCM thickness 
measurement system (Inficon) during the growth process. Also, the thickness of the films was further verified with cross-sectional SEM imaging.

\subsection{Growth of Ag NSs}

Si (100) substrates $\left(1 \times 1 \mathrm{~cm}^{2}\right)$ with a $250 \mathrm{~nm}$ thick film of $\mathrm{ZnO}$ were immersed into a dopamine solution (dopamine hydrochloride (Sigma H8502), $1 \mathrm{mg} / \mathrm{mL}$ in $5 \mathrm{mM}$ Tris-EDTA buffer, $\mathrm{pH}$ 8.5) at room temperature for $2 \mathrm{~h}$. After the polydopamine (PD) coating, the samples were washed with distilled water. After the cleaning samples were dried by blowing $\mathrm{N}_{2}$ gas. Then, PD coated substrates were treated with silver nitrate solution ( $50 \mathrm{mM} \mathrm{AgNO} 3$ in $15 \mathrm{~mL}$ distilled water) in an orbital shaker system for different $\mathrm{Ag}$ growth times (12, 24 and 36h).

\subsection{Characterization}

The X-ray diffraction patterns of multi-functional thin films were analyzed using Grazing Incident X-ray diffraction (GIXRD) technique with Panalytical X-ray diffractometer in $2 \theta$ range of 30-80. Microstructural, surface morphology and elemental analysis of the thin films were investigated using Field Emission Scanning Electron Microscope (FESEM, Zeiss Gemini 500). FTIR spectrum measurements of samples were taken in the range of 450-4000 $\mathrm{cm}^{-1}$ using Fouirer Transform Infrared Spectrometer (Perkin Elmer Spotlight 400 Imaging System). Perkin Elmer Lambda 25 was used as a UV-vis spectroscopy in the wavelength range of $300-650 \mathrm{~nm}$ to monitor the catalytic degradation of methyl orange (MO) and rhodamine $\mathrm{B}(\mathrm{RhB})$. For catalytic degradation, dye molecules (MO \& RhB) dissolved in aqueous solutions were prepared at a concentration of $1 \mathrm{mg} / 100 \mathrm{ml}$. Before positioning the substrate in the solution, $1 \mathrm{M}$ $\mathrm{NaBH}_{4}$ freshly prepared in cold water was added to the solution while stirring and first absorbance spectrum was measured with UV-visible spectroscopy at this time. Then, the substrate was located on the holder in a glass beaker filled with $100 \mathrm{ml}$ of solution. After that, the absorbance spectrum of the solution was measured at varying times $(5,10,15,20,25,30,45$ and $60 \mathrm{~min}$.).

\section{RESULTS}

Figure 1 summarizes the growth of Ag NSs on top of sputter-coated films of $\mathrm{ZnO}$. The first step consisted of deposition of a thin film of $\mathrm{ZnO}$ via $\mathrm{RF}$ magnetron sputtering. In order to decorate the $\mathrm{ZnO}$ thin film with Ag nanostructures, the substrate was functionalized with mussel inspired PD coating. The deposition of PD was simply performed by immersing the substrate in a buffered solution of dopamine. The selfpolymerization of dopamine on the surface of solid substrates resulted in a layer of PD with a thickness that scaled with the immersion time. The thickness of the PD layer following $2 \mathrm{~h}$ was found to be $2.1 \pm 0.1 \mathrm{~nm}$. The catechol groups that are present in the PD layer provides reactive sites for reduction of metal salts [23]. In a solution of $\mathrm{AgNO}_{3}$, the substrate was decorated with $\mathrm{Ag}$ NSs. The growth of $\mathrm{Ag}$ NSs occurred in regions with an average diameter of $1.6 \pm 0.8 \mu \mathrm{m}$. The high magnification SEM imaging revealed the growth of columnar structures within these regions. 


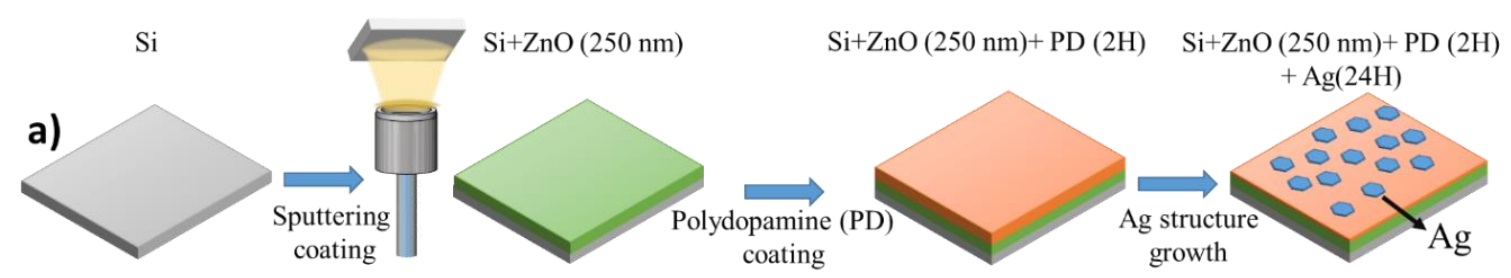

b)

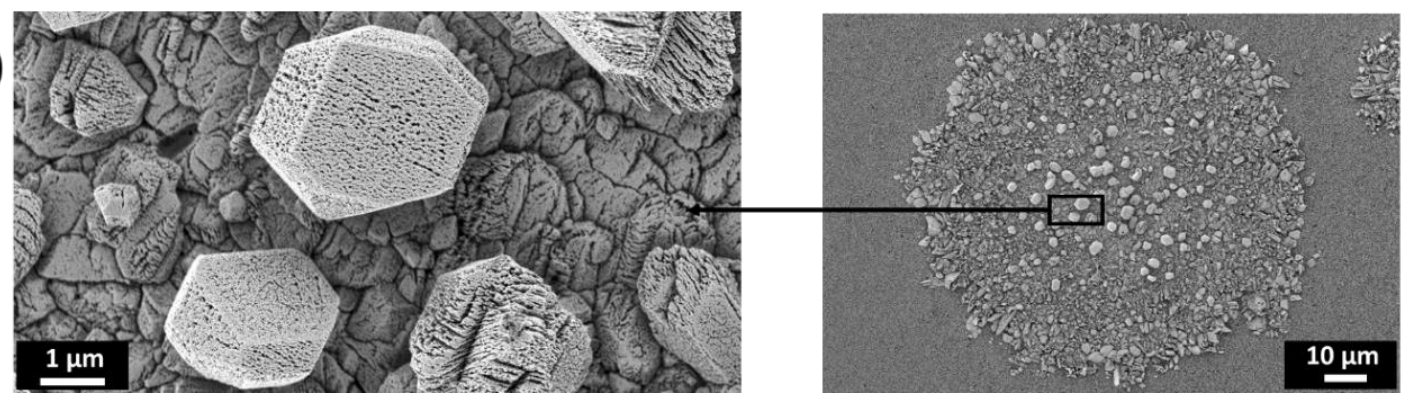

Figure 1. Growth of Ag NSs on top of ZnO thin films; a) Schematic description of the process b) SEM images of the Ag NSs

\subsection{Structural Characterization Results}

The XRD pattern for pure and $\mathrm{Ag}$ decorated $\mathrm{ZnO}$ thin films for various $\mathrm{Ag}$ deposition times showed in Figure 2. The (002) and (130) planes corresponding to the diffraction peaks at $34.2^{\circ}$ and $62.6^{\circ}$ indicate that the $\mathrm{ZnO}$ films are good agreement with the wurtzite hexagonal crystal structure (JCPDS No. 36-1451) [24]. These peaks were not present in the absence of $\mathrm{ZnO}$ thin film for the PD coated, and Ag decorated PD thin films. The peak at $38.2^{\circ}$ was attributed to diffraction from the (111) plane of face centered cubic structure Ag (JCPDS card \# 089-3722) [20]. The peak intensity of the Ag on the uncoated PD on ZnO film was quite low. The maximum peak intensity for $\mathrm{ZnO}$ and $\mathrm{Ag}$ was observed for the substrates prepared by using $24 \mathrm{~h}$ $\mathrm{Ag}$ deposition time. The peak intensity of the $\mathrm{ZnO}$ (002) plane increases with the $\mathrm{Ag}$ decoration time. But, after 24h, the intensity of the peak decreased despite the increase in Ag decoration time. This indicates that decorating the $24 \mathrm{~h} \mathrm{Ag}$ may improve $\mathrm{ZnO}$ (002) preference orientation but decorating the $\mathrm{Ag}$ for too long disrupts the orientation. In addition, the radius of the $\mathrm{Ag}^{+}$ion $(1.22 \AA)$ is larger than the radius of the $\mathrm{Zn}^{2+}$ ions $(0.74 \AA)$. When the $\mathrm{Ag}$ decoration time exceeds $24 \mathrm{~h}, \mathrm{Ag}$ occupies the interstitial regions of $\mathrm{ZnO}$ and preventing the $\mathrm{ZnO}$ film from growing in the direction of the $\mathrm{c}$-axis.

The average crystallite sizes (D) of the samples were calculated using the Debye-Scherrer equation [25]

$D=\frac{0.9 \lambda}{\beta \cos \theta}$

where $\lambda, \theta$ and $\beta$ is the wavelength of X-ray radiation, Bragg's angle of the peaks and the angular width of peaks at FWHM, respectively. The average crystal size of pure $\mathrm{ZnO}$ was $7.7 \mathrm{~nm}$, and this size varied with the Ag deposition time. The average crystallite size was $9.93 \mathrm{~nm}, 12.76 \mathrm{~nm}$ and $10.86 \mathrm{~nm}$ for $\mathrm{ZnO}$ films that were decorated with $\mathrm{Ag}$ for $12 \mathrm{~h}, 24 \mathrm{~h}$ and $36 \mathrm{~h}$, respectively. The absence of any additional peaks and shifts in the position of peaks suggests that $\mathrm{Ag}$ did not incorporate into the lattice of $\mathrm{ZnO}$ but were only present on the surface of $\mathrm{ZnO}[26,27]$. 


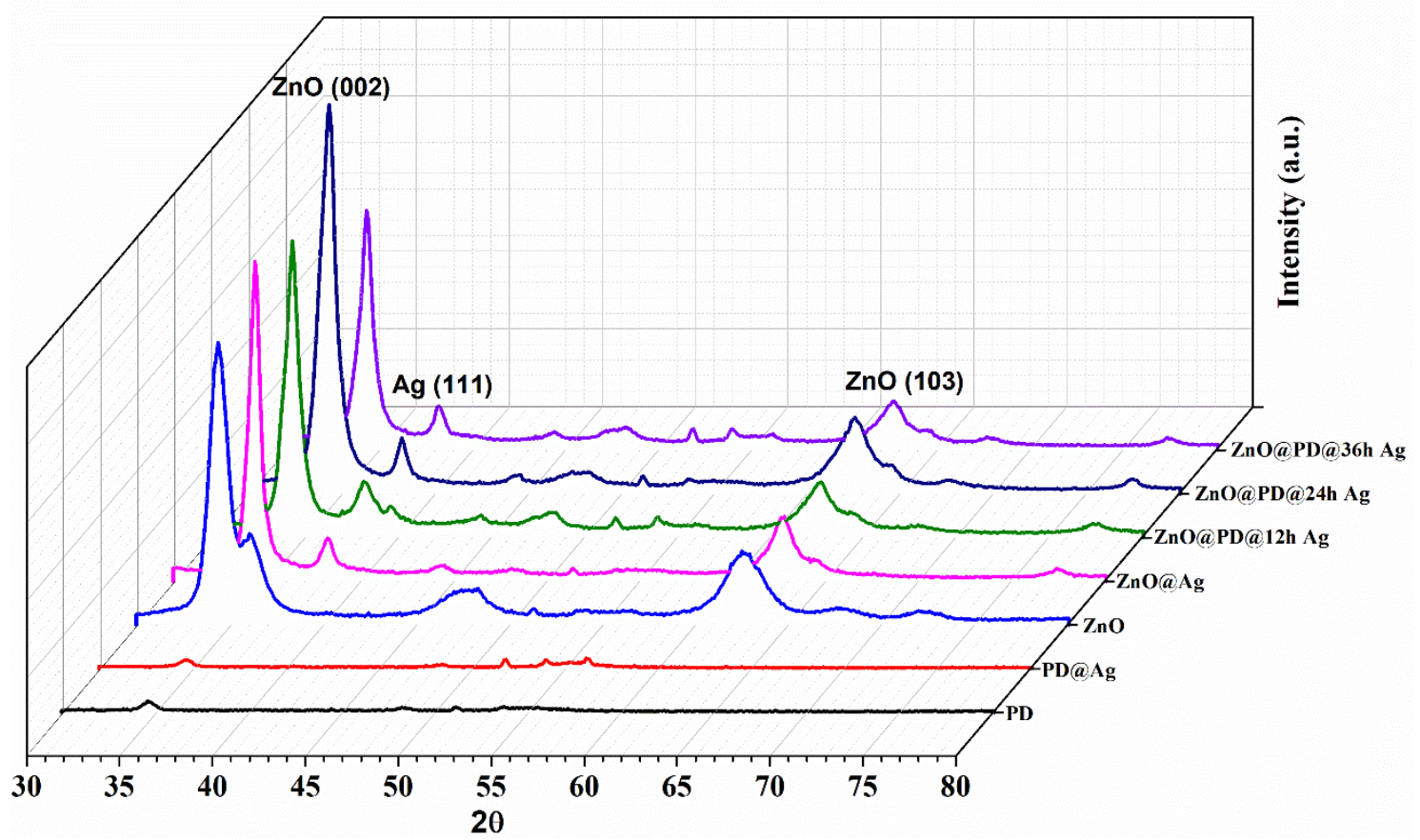

Figure 2. X-ray diffraction pattern of pure and $\mathrm{Ag}$ decorated $\mathrm{ZnO}$ thin films for varying Ag deposition times

SEM imaging was used for morphological characterization of as deposited and $\mathrm{Ag}$ decorated $\mathrm{ZnO}$ thin films. Figure 3 presents SEM images of pure and $\mathrm{Ag}$ decorated $\mathrm{ZnO}$ thin films prepared at different conditions. The $\mathrm{ZnO}$ film was highly uniform, free of any cracks, and consisted of nanoscale grains. The morphology of the surface exhibited significant change with the deposition of Ag. Control experiments in the absence of the PD coating did not result in the growth of Ag NSs. When PD was deposited on ZnO films, this layer allowed the growth of Ag NSs on the surface. The morphology of the substrates as a function of the Ag deposition time was investigated. The size of the Ag NSs was changed by growth time. When the growth time was $12 \mathrm{~h}$, the formation of Ag NSs was not complete. When the growth time increased to $24 \mathrm{~h}, \mathrm{Ag}$ NSs formed with an average size of $374 \mathrm{~nm}$. Increasing the growth time to $36 \mathrm{~h}$, the average size of $\mathrm{Ag}$ NSs was reduced to $286 \mathrm{~nm}$, likely due to the degradation of the underlying $\mathrm{ZnO}$ film in the aqueous growth solution. The growth of $\mathrm{Ag} \mathrm{NSs} \mathrm{on} \mathrm{ZnO}$ film can be explained by metal ion reduction capabilities of PD. In the absence of PD, Ag nanostructures did not grow on the $\mathrm{ZnO}$ film. This result suggests the necessity of the functional groups provided by PD for the surface growth of Ag NSs. The growth of Ag was confined in micrometer sized regions. This localized growth is likely a result of the defect sites in the functionalization of the $\mathrm{ZnO}$ film with PD. 

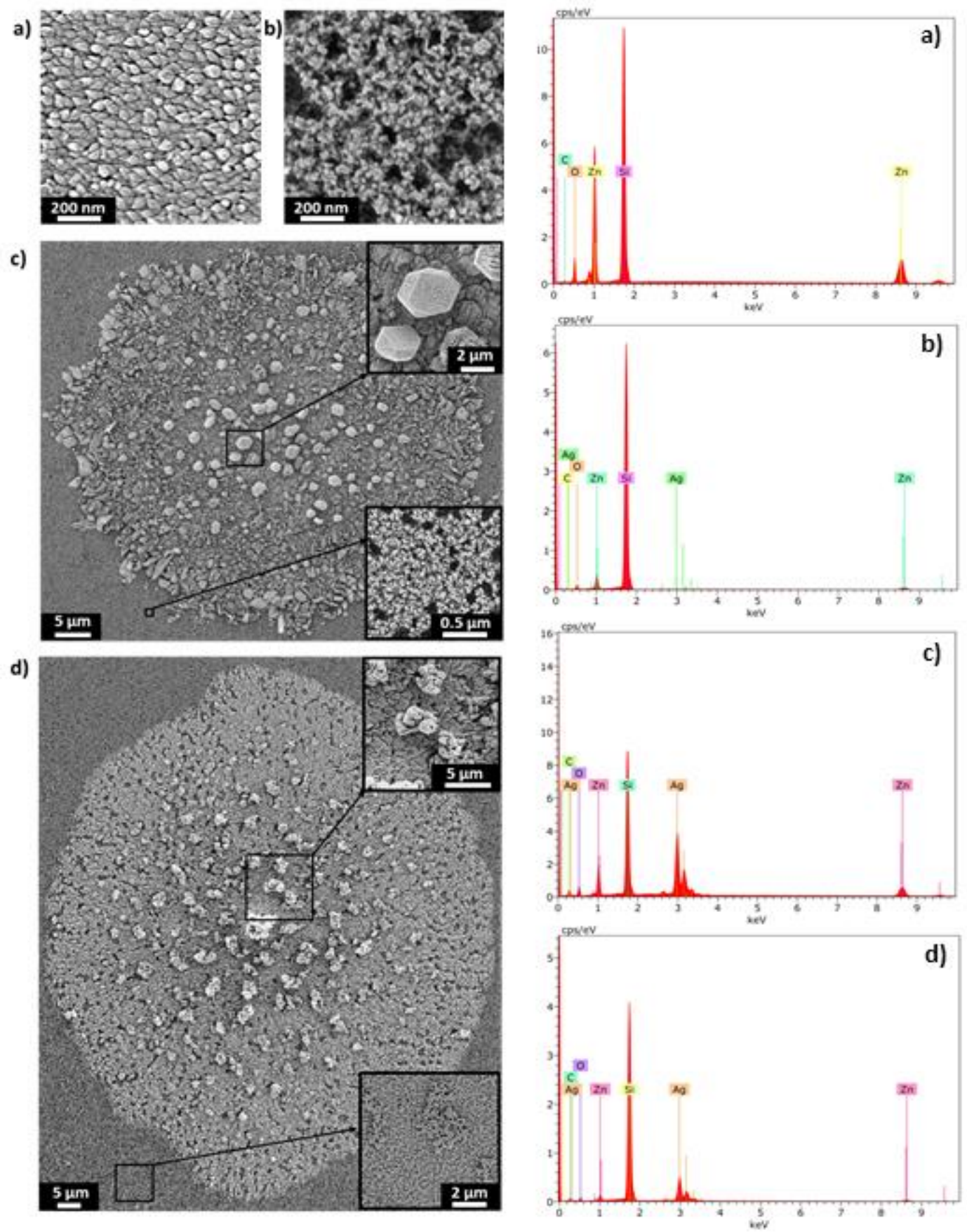

Figure 3. SEM images and EDX results of the substrates; a) As-deposited ZnO b) ZnO@PD@12h Ag c) ZnO@PD@24h Agd) ZnO@PD@36h Ag

The chemical compositions of the as-deposited and $\mathrm{Ag}$ decorated $\mathrm{ZnO}$ thin films obtained from the EDX spectrum are shown in Figure 3. The elemental composition from the EDX spectrum confirmed the presence of $\mathrm{Zn}, \mathrm{O}$ and $\mathrm{Ag}$ in the fabricated samples. The results show that Ag nanoparticles were successfully decorated on $\mathrm{ZnO}$ thin films.

The FTIR spectrum of as-deposited and $\mathrm{Ag}$ decorated $\mathrm{ZnO}$ thin films for varying $\mathrm{Ag}$ deposition times are shown in Figure 4. FTIR is a technique used to obtain information about the chemical bond structure of a material and to quickly establish the presence of various vibration modes in the samples. This technique is used to describe the main components of the material. The numbers and positions of the absorption peaks depend on the chemical composition, crystal structure and morphology of thin films. As-deposited $\mathrm{ZnO}$ and $\mathrm{Ag}$ decorated $\mathrm{ZnO}$ has a wurtzite crystal structure and this result is supported by the FTIR spectrum shown in Figure 4. 
As seen in Figure 4, various vibration modes have been observed in different regions of the FTIR spectrum. The peak at $554 \mathrm{~cm}^{-1}$ is the typical characteristic peak of the pure $\mathrm{ZnO}$ hexagonal phase [28]. The peak at $1059 \mathrm{~cm}^{-1}$ is attributed to $\mathrm{Si}-\mathrm{O}-\mathrm{Si}$ bonds resulting from the silicon substrate. The vibration stress mode of the $\mathrm{C}=\mathrm{O}$ bond was obtained at $1400 \mathrm{~cm}^{-1}$. The absorption peak observed in $2338 \mathrm{~cm}^{-1}$ results from the atmospheric $\mathrm{CO}_{2}$. The peaks in $2914 \mathrm{~cm}^{-1}$ and $2970 \mathrm{~cm}^{-1}$ correspond to the stretching mode of the methylene groups.

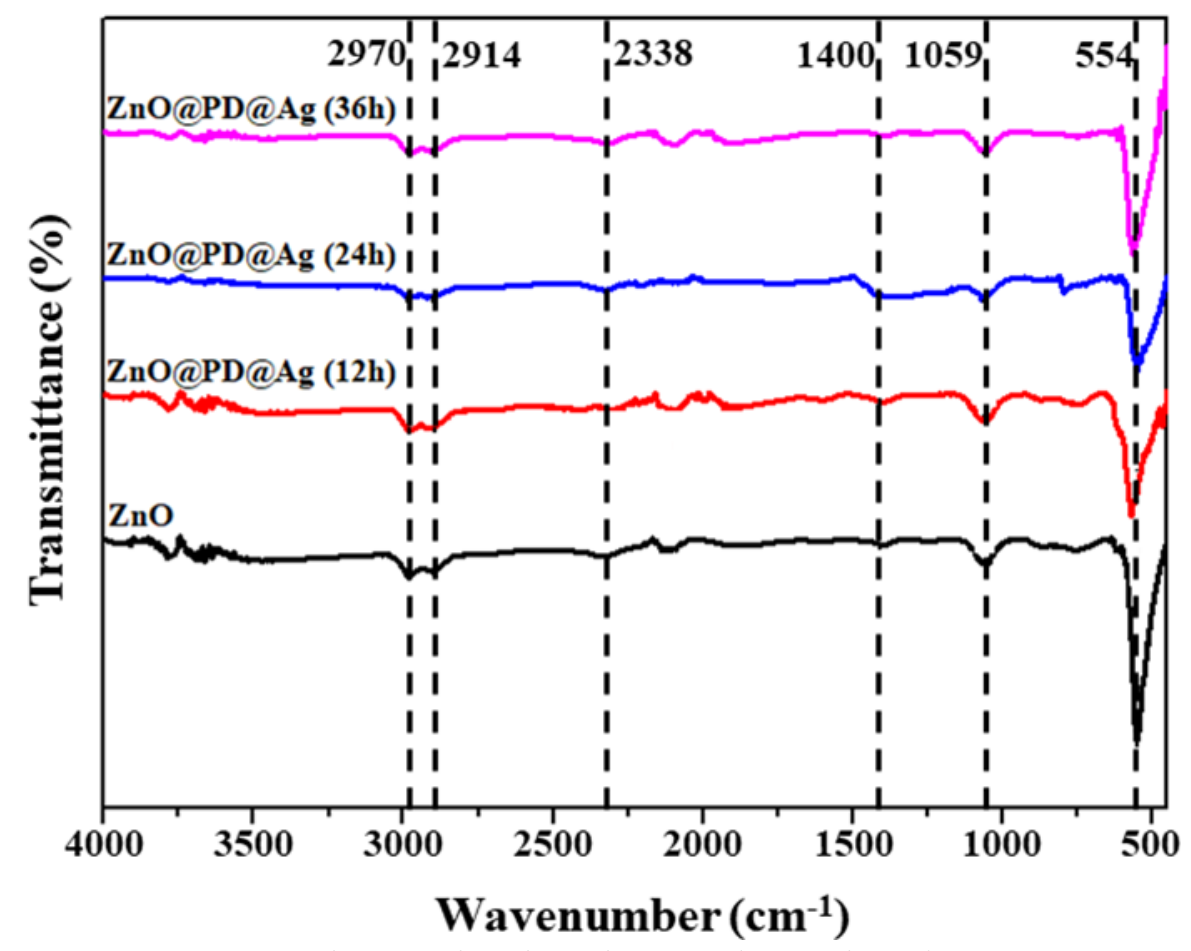

Figure 4. FTIR spectrum of as-deposited and $\mathrm{Ag}$ decorated $\mathrm{ZnO}$ thin films for varying $\mathrm{Ag}$ deposition times

\subsection{Catalytic Performance}

As-deposited and Ag decorated $\mathrm{ZnO}$ films absorption spectra at room temperature are given in Figure 5 (a). The absorption peaks around the $360 \mathrm{~nm}$ wavelength are the characteristic peak of $\mathrm{ZnO}$. These absorption spectra showed that the films decorated with $\mathrm{Ag}$ shift the light absorption edge to red compared to pure $\mathrm{ZnO}$, and this shift level increases with the Ag decoration time. Reduction of light absorption to red is a result of a decrease in band gap energy. This is due to Ag with a lower Fermi energy than ZnO. The catalytic degradation activities of the multi-functional thin films were analyzed in the absence and presence of the reducing agent. UV-visible absorption spectrums of $\mathrm{MO}$ and $\mathrm{RhB}$ solution taken at different times are shown in Figure 5 (b), (c). As clearly seen in Figure 5 (b), (c), the absorbance decreases for both MO and $\mathrm{RhB}$ dyes in the presence of $\mathrm{NaBH}_{4}$. Before the addition of $\mathrm{NaBH}_{4}$, the maximum absorbance peaks appeared at wavelengths of $464 \mathrm{~nm}$ and $553 \mathrm{~nm}$ for $\mathrm{MO}$ and $\mathrm{RhB}$, respectively. 

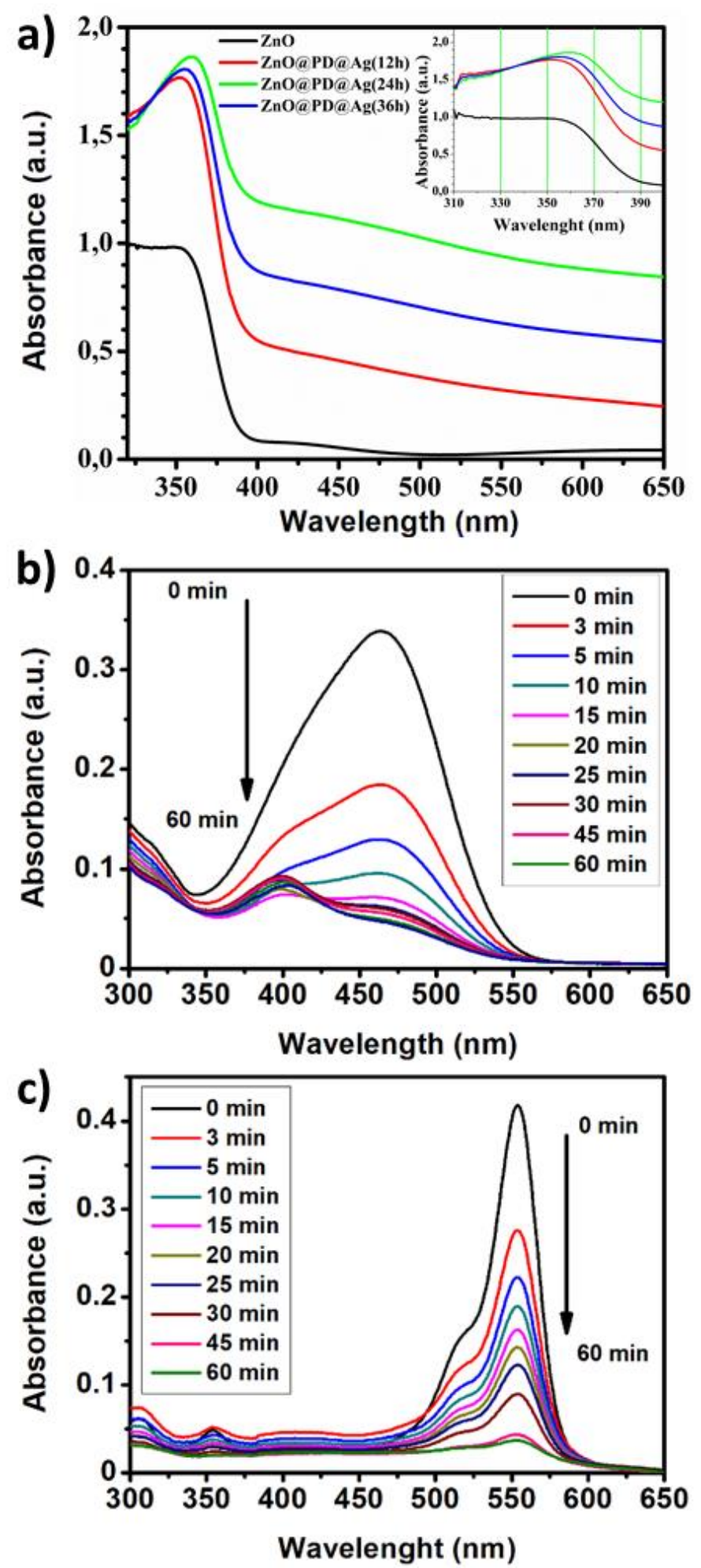

Figure 5. a) Uv-Visible absorption spectrum of samples; Time-dependent UV spectra of $24 \mathrm{~h} \mathrm{Ag}$ decorated $\mathrm{ZnO}$ thin films in different reducing agents $b$ ) $M O$ c) $R h B$

When the reducing agent was added to the dye solution where $\mathrm{Ag}$ decorated $\mathrm{ZnO}$ thin film was present, the absorption peaks were reduced over time. Especially for $\mathrm{MO}$, with the addition of $\mathrm{NaBH}_{4}$, the degradation occurred at high rates in the first $5 \mathrm{~min}$. This high rate of degradation can be related with the interaction of $\mathrm{RhB}$ and the reducing agent with the catalytically active regions. 
a)

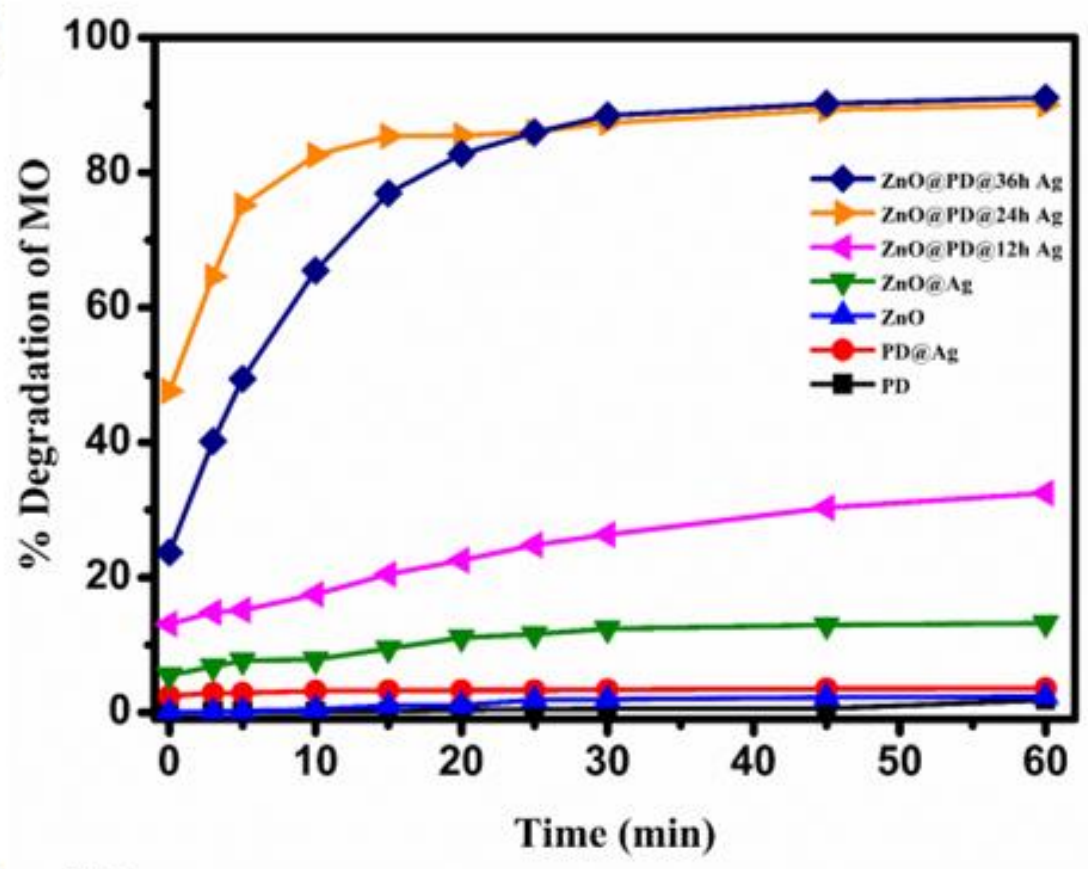

b)

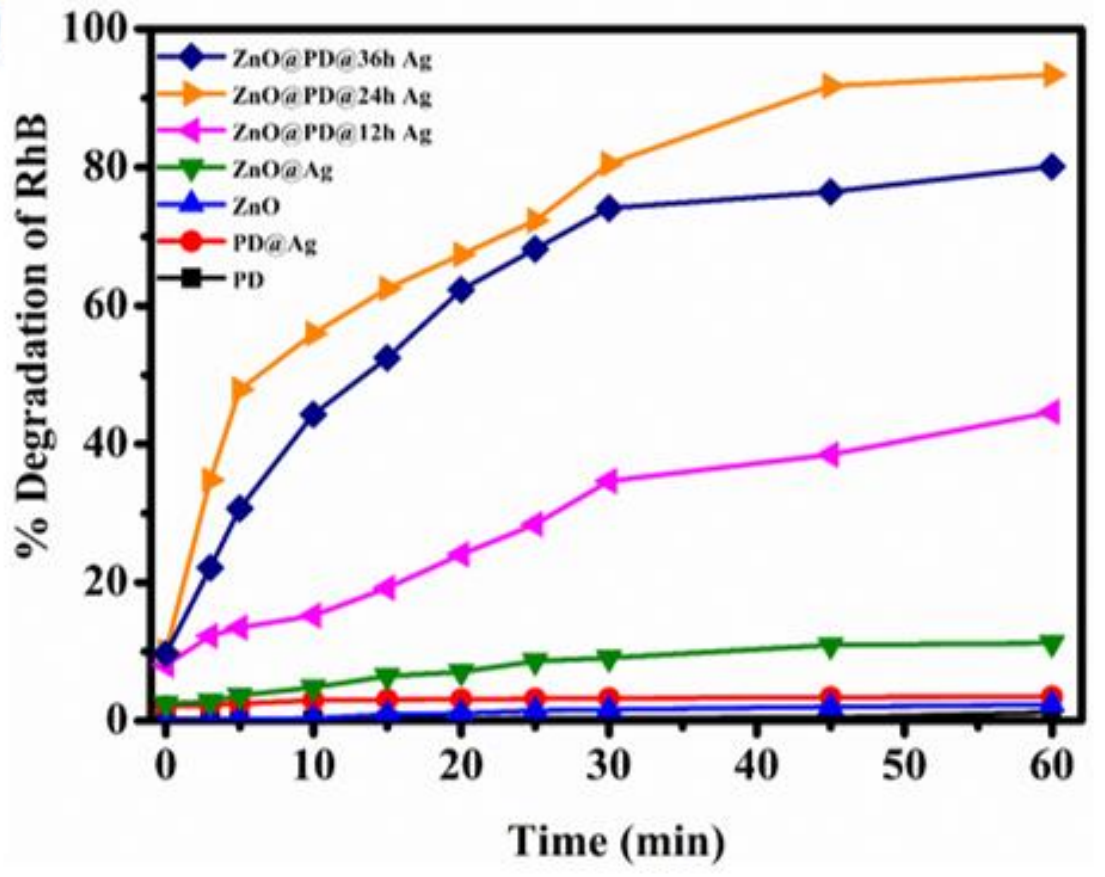

Figure 6. The degradation percentage of $M O$ and $R h B$ was changed by the Ag NSs growth; a) MO b) $R h B$

The catalytic performance of the $\mathrm{Ag}$ decorated $\mathrm{ZnO}$ thin films depended on the Ag growth time. Figure 6 shows, the degradation percentage of $\mathrm{MO}$ and $\mathrm{RhB}$ was changed by the $\mathrm{Ag}$ NSs growth times. For substrates with PD, PD@Ag and ZnO thin films, the degradation percentage was below 20\% for MO after 60 minutes, while for $\mathrm{RhB}$ it was below $10 \%$. The degradation reaction proceeded rapidly in the case of substrates that involve both $\mathrm{ZnO}$ film and $\mathrm{Ag}$ NSs.

At the end of $15 \mathrm{~min}$, for $\mathrm{ZnO}$ films that were decorated with $\mathrm{Ag}$ for $12 \mathrm{~h}, 24 \mathrm{~h}$ and $36 \mathrm{~h}$, the degradation percentage of the MO were $20 \%, 86 \%$ and $76 \%$, whereas the degradation percentage of $\mathrm{RhB}$ were $19 \%$, $62 \%$ and $53 \%$, respectively. These results confirm the synergistic effect of the metal oxide thin films with plasmonic nanostructures. The maximum degradation was observed for $24 \mathrm{~h} \mathrm{Ag}$ deposition on $\mathrm{ZnO}$ thin film. For this film, the total degradation percentage was $90 \%$ at the end of $60 \mathrm{~min}$. Although the maximum degradation was observed for the $24 \mathrm{~h} \mathrm{Ag}$ decorated sample at the end of the first $15 \mathrm{~min}$, the total 
degradation at the end of the 60 min was $91 \%$ with the $36 \mathrm{~h} \mathrm{Ag} \mathrm{decorated} \mathrm{sample.} \mathrm{We} \mathrm{have} \mathrm{also} \mathrm{performed}$ degradation experiments using different dye molecules.

Figure 7 compares the degradation percentage of $24 \mathrm{~h} \mathrm{Ag}$ decorated $\mathrm{ZnO}$ thin films in $\mathrm{RhB}$ and $\mathrm{MO}$. At the end of the first 15 min., the degradation percentage of $\mathrm{RhB}$ was observed at $62 \%$. In the experiments carried out here, at the end of $60 \mathrm{~min} ., 90 \%$ degradation in $\mathrm{MO}$ and $94 \%$ degradation in $\mathrm{RhB}$ was observed. Consideration of these results with SEM images shows the importance of the size of the nanostructures for the catalytic performance. At the short growth times, there were no growth of Ag NSs, which resulted in low catalytic activity. In contrast, at longer growth times, the reduction in the size of Ag NSs led to decrease in the catalytic performance of the substrates.

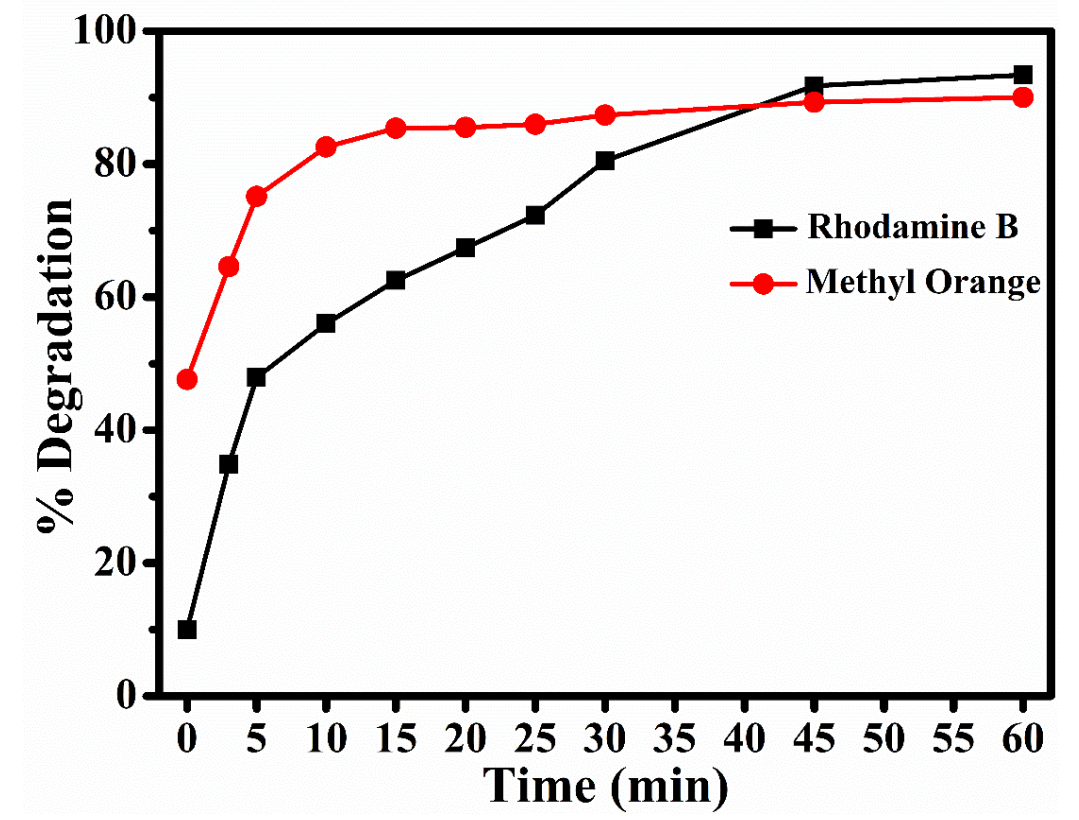

Figure 7. The degradation percentage of $24 \mathrm{~h} \mathrm{Ag}$ decorated $\mathrm{ZnO}$ thin films for $\mathrm{RhB}$ and $M O$

\subsection{Degradation kinetics of methyl orange and rhodamine $B$}

The kinetics of the catalytic degradation reaction of $\mathrm{ZnO}$ thin films decorated with $\mathrm{Ag}$ for 24 hours was analyzed using RhB and MO. The kinetic data of catalytic degradation of organic dyes with Ag decorated $\mathrm{ZnO}$ catalyst are analyzed by various models [29]. Langmuir-Hinshelwood mechanism forms the basis of these models [30]. The kinetics of heterogeneous catalytic systems given by Equation (2) are defined by Langmuir-Hinshelwood

$\ln \left(\frac{C_{0}}{C}\right)+K\left(C_{0}-C\right)=k_{a p p} K t$

Here, $\mathrm{C}$ is the concentration of dye molecules after degradation, $\mathrm{C}_{0}$, initial concentration of dye molecules, $\mathrm{K}$ adsorption equilibrium constant, $\mathrm{k}_{\text {app }}$ apparent reaction rate constant and $\mathrm{t}$ catalytic processing time. In diluted $\left(\mathrm{C}<10^{-3} \mathrm{M}\right)$ solutions, the reaction takes place in order to comply with the first order kinetics given by, since the $\mathrm{KC}$ in Equation (2) will be $<<1$

$\ln \left(\frac{C}{C_{0}}\right)=-k_{a p p} t$

The absorbances of MO and RhB can be measured at approximately $464 \mathrm{~nm}$ and $554 \mathrm{~nm}$, respectively. In this case, as a result of catalytic activity tests, the concentration values are calculated by Equation (4).

$\ln \left(\frac{C}{C_{0}}\right)=\ln \left(\frac{A}{A_{0}}\right)=-k_{a p p} t$, 
where $\mathrm{A}$ is the initial absorbance of the dye molecules at 464 and $554 \mathrm{~nm}$, and $\mathrm{A}_{0}$ is the final absorbance. Figure 8 shows that the plot of $\ln \left(\mathrm{A} / \mathrm{A}_{0}\right)$ against degradation time for $24 \mathrm{~h} \mathrm{Ag}$ decorated $\mathrm{ZnO}$ thin films in Rhodamine B and Methyl Orange. As clearly seen from Figure 8, the degradation reactions correspond to the first-order reaction mechanism. The apparent reaction rate constant $\mathrm{k}_{\mathrm{app}}$, was calculated from the slope of the linear fit to the plot. The reaction rate constant was $33.8 \times 10^{-3} \mathrm{~min}^{-1}$ for MO and $43.2 \times 10^{-3} \mathrm{~min}^{-1}$ for $\mathrm{RhB}$. The reaction rate constant of $\mathrm{RhB}$ is greater than reaction rate constant of $\mathrm{MO}$. According to the degradation test results using $24 \mathrm{~h} \mathrm{Ag}$ decorated $\mathrm{ZnO}$ thin films, it was observed that the degradation of $\mathrm{RhB}$ is higher than $\mathrm{MO}$.

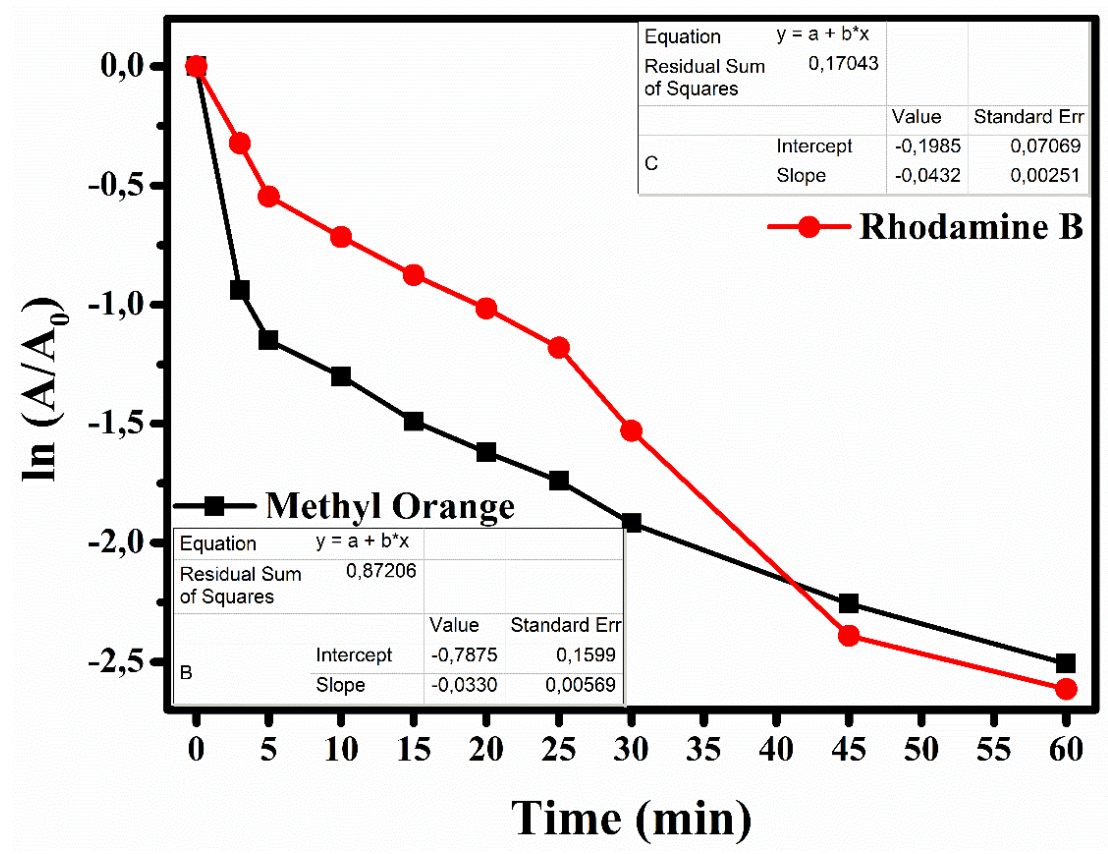

Figure 8. The variation of $\ln (\mathrm{A} / \mathrm{AO})$ as a function of time for $24 \mathrm{~h} \mathrm{Ag}$ decorated $\mathrm{ZnO}$ thin films in $\mathrm{RhB}$ and $M O$

A general mechanism for degradation of $\mathrm{MO}$ and $\mathrm{RhB}$ is shown in Figure 9. The catalytic degradation process is based on the transfer of electrons from the donor $\left(\mathrm{NaBH}_{4}\right)$ to the acceptor $(\mathrm{MO}$ and $\mathrm{RhB})$. Simultaneous absorption of both dyes and $\mathrm{BH}_{4}^{-}$ions on the surface of nanostructures is the beginning of degradation. When $\mathrm{MO}$ and $\mathrm{RhB}$ are reduced by $\mathrm{NaBH}_{4}$ in the presence of catalyst, these dyes can decompose to form cationic species. The functional group of these dye molecules can be adsorbed on the surface of $\mathrm{Ag} @ \mathrm{ZnO}$ nanocomposites. As soon as $\mathrm{BH}_{4}^{-}$ions supply electrons to $\mathrm{Ag} @ \mathrm{ZnO}$ nanocomposites, these electrons accumulate in Ag NPs and are trapped by adsorbed oxygen molecules to form $O_{2}^{*}$ and ${ }^{*} \mathrm{OH}$ radicals $[15,20,22]$. These radicals react with the functional group of $\mathrm{MO}$ and $\mathrm{RhB}$ adsorbed, destroying the molecular structure of the dyes. This indicates that dyes $(\mathrm{MO} \& \mathrm{RhB})$ and $\mathrm{BH}_{4}$ ions are absorbed simultaneously by $\mathrm{Ag} @ \mathrm{ZnO}$ nanocomposites and catalysts facilitate electron transfer. As a result, electron charge transfer from $\mathrm{BH}_{4}^{-}$ion to dyes can occur through $\mathrm{Ag} @ \mathrm{ZnO}$ nanocomposites. The high catalytic activity of $\mathrm{Ag}$ decorated $\mathrm{ZnO}$ samples is related to the irregular shapes of Ag nanostructures, large surface area /volume ratio and high surface area. These properties facilitate electron transfer and allow to exceed the kinetic barrier for the degradation reaction. 


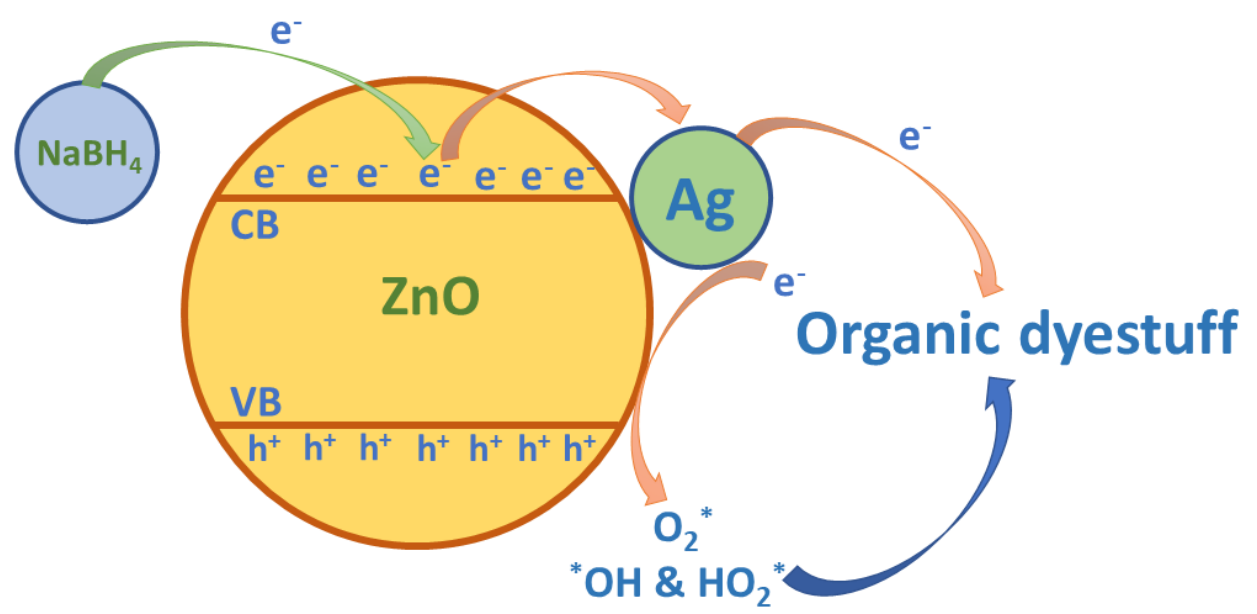

Figure 9. Catalytic reaction mechanism

\section{CONCLUSION}

Multi-functional surfaces were fabricated by physical vapor deposition of $\mathrm{ZnO}$ thin films followed by solution-phase PD mediated growth of Ag NSs. The synergistic effects between metal oxide semiconductor and plasmonic metallic nanostructures allowed for rapid degradation of two different types of organic dye molecules. The growth time of Ag NSs was important for obtaining high levels of degradation efficiency. The use of a universal surface functionalization agent, PD, offers the possibility of applying the presented approach to other types of metal oxide films and metallic structures. The ease of separation and possibility of reusing the substrates are the key advantages of solid substrates for degradation applications.

\section{CONFLICTS OF INTEREST}

No conflict of interest was declared by the authors.

\section{REFERENCES}

[1] Grassi, M., Kaykioglu, G., Belgiorno, V. and Lofrano, G., "Removal of Emerging Contaminants from Water and Wastewater by Adsorption Process Emerging Compounds Removal from Wastewater: Natural and Solar Based Treatments", Springer, Netherlands: Dordrecht, (2012).

[2] Kümmerer, K., "The presence of pharmaceuticals in the environment due to human use-present knowledge and future challenges", Journal of Environmental Management, 90(8): 2354-2366, (2009).

[3] Robinson, T., McMullan, G., Marchant, R. and Nigam, P., "Remediation of dyes in textile effluent: a critical review on current treatment technologies with a proposed alternative", Bioresource Technology, 77(3): 247-255, (2001).

[4] Ghosh, B. K., Hazra, S., Naik, B. and Ghosh, N. N., "Preparation of Cu nanoparticle loaded SBA-15 and their excellent catalytic activity in reduction of variety of dyes", Powder Technology, 269: 371$378,(2015)$.

[5] Singh, K. and Arora, S., "Removal of synthetic textile dyes from wastewaters: A critical review on present treatment technologies", Critical Reviews in Environmental Science and Technology, 41(9): 807-878, (2011). 
[6] Dong, W., Zhu, Y., Huang, H., Jiang, L., Zhu, H., Li, C., Chen, B., Shi, Z. and Wang, G., “A performance study of enhanced visible-light-driven photocatalysis and magnetical protein separation of multifunctional yolk-shell nanostructures", Journal of Materials Chemistry A, 1(34): 1003010036, (2013).

[7] Chen, F., Ho, P., Ran, R., Chen, W., Si, Z., Wu, X., Weng, D., Huang, Z. and Lee, C., "Synergistic effect of $\mathrm{CeO}_{2}$ modified $\mathrm{TiO}_{2}$ photocatalyst on the enhancement of visible light photocatalytic performance", Journal of Alloys and Compounds, 714: 560-566, (2017).

[8] Kumar, D. R., Ranjith, K. S., Nivedita, L. R., Asokan, K. and Kumar, R. T. R., "Swift heavy ion induced effects on structural, optical and photo-catalytic properties of Ag irradiated vertically aligned ZnO nanorod arrays", Nuclear Instruments and Methods in Physics Research Section B, 450: 95-99, (2019).

[9] Chakrabarti, S. and Dutta, B. K., "Photocatalytic degradation of model textile dyes in wastewater using $\mathrm{ZnO}$ as semiconductor catalyst”, Journal of Hazardous Materials, 112(3): 269-278, (2004).

[10] Veziroglu, S., Kuru, M., Ghori, M. Z., Dokan, F. K., Hinz, A. M., Strunskus, T., Faupel, F. and Aktas, O. C., "Ultra-fast degradation of methylene blue by $\mathrm{Au} / \mathrm{ZnO}-\mathrm{CeO}_{2}$ nano-hybrid catalyst", Materials Letters, 209: 486-491 (2017).

[11] Whang, T. J., Hsieh, M. T. and Chen, H. H., "Visible-light photocatalytic degradation of methylene blue with laser-induced Ag/ZnO nanoparticles", Applied Surface Science, 258: 2796-2801, (2012).

[12] Zhang, P., Chen, Y., Yang, X., Gui, J., Li, Y., Peng, H., Liu, D. and Qiu, J., "Pt/ZnO@C nanocable with dual-enhanced photocatalytic performance and superior photostability", Langmuir, 33: 44524460, (2017).

[13] Muñoz-Fernandez, L., Sierra-Fernandez, A., Milošević, O. and Rabanal, M. E., "Solvothermal synthesis of $\mathrm{Ag} / \mathrm{ZnO}$ and $\mathrm{Pt} / \mathrm{ZnO}$ nanocomposites and comparison of their photocatalytic behaviors on dyes degradation", Advanced Powder Technology, 27(3): 983-993, (2016).

[14] Wang, L., Hu, Q., Li, Z., Guo, J., and Li, Y., "Microwave-assisted synthesis and photocatalytic performance of Ag-doped hierarchical ZnO architectures", Materials Letters, 79: 277-280, (2012).

[15] Wang, Y., Arandiyan, H., Scott, J., Bagheri, A., Dai, H. and Amal, R., "Recent advances in porous metal oxides for heterogeneous catalysis: a review", Journal of Materials Chemistry A, 5: 8825-8846, (2017).

[16] Gupta, V. K. and Nayak, A., "Cadmium removal and recovery from aqueous solutions by novel adsorbents prepared from orange peel and $\mathrm{Fe}_{2} \mathrm{O}_{3}$ nanoparticles", Chemical Engineering Journal, 180: 81-90, (2012).

[17] Mallick, K., Witcomb, M. J. and Scurrell, M. S., "Redox catalytic property of gold nanoclusters: evidence of an electron-relay effect”, Applied Physics A Materials Science \& Processing, 80: 797801, (2005). 
[18] Gupta, N., Singh, H. P., and Sharma, R. K., "Metal nanoparticles with high catalytic activity in degradation of methyl orange: An electron relay effect", Journal of Molecular Catalysis A: Chemical, 335(1-2): 248-252, (2011).

[19] Khan, M. M., Lee, J., and Cho, M.H., “Au@ $@ \mathrm{TiO}_{2}$ nanocomposites for the catalytic degradation of methyl orange and methylene blue: An electron relay effect". Industrial \& Engineering Chemistry Research, 20(4): 1584-1590, (2014).

[20] Şakir, M., and Onses, M. S., "Solid substrates decorated with Ag nanostructures for the catalytic degradation of methyl orange", Results in Physics, 12: 1133-1141, (2019).

[21] Abed, C., Bouzidi, C., Elhouichet, H., Gelloz, B., and Ferid, M., "Mg doping induced high structural quality of sol-gel ZnO nanocrystals: Application in photocatalysis", Applied Surface Science, 349: 855-863, (2015).

[22] Kuru, M. and Narsat, H., "The effect of heat treatment temperature and Mg doping on structural and photocatalytic activity of $\mathrm{ZnO}$ thin films fabricated by RF magnetron co-sputtering technique", Journal of Materials Science: Materials in Electronics, 30(20): 18484-18495 (2019).

[23] Lee, H., Dellatore, S. M., Miller, W. M. and Messersmith, P. B., "Mussel-Inspired Surface Chemistry for Multifunctional Coatings", Science, 318(5849): 426-430, (2007).

[24] Rafaie, H. A., Nor, R. M., Azmina, M. S., Ramli, N. I. T. and Mohamed, R., "Decoration of ZnO microstructures with Ag nanoparticles enhanced the catalytic photodegradation of methylene blue dye", Journal of Environmental Chemical Engineering, 5(4): 3963-3972, (2017).

[25] Cullity, B. D. and Graham, C. D., "Introduction to Magnetic Materials", Wiley, (2009).

[26] Jayram, N. D., Sonia, S., Poongodi, S., Kumar, P. S., Masuda, Y., Mangalaraj, D., Ponpandian, N. and Viswanathan C., "Superhydrophobic Ag decorated $\mathrm{ZnO}$ nanostructured thin film as effective surface enhanced Raman scattering substrates", Applied Surface Science, 355: 969-977, (2015).

[27] Fageria, P., Gangopadhyay, S. and Pande, S., "Synthesis of $\mathrm{ZnO} / \mathrm{Au}$ and $\mathrm{ZnO} / \mathrm{Ag}$ nanoparticles and their photocatalytic application using UV and visible light", RSC Advances, 4: 24962-24972, (2014).

[28] Sornalatha, J. D. and Murugakoothan, P., "Characterization of hexagonal $\mathrm{ZnO}$ nanostructures prepared by hexamethylenetetramine (HMTA) assisted wet chemical method", Materials Letters, 124: 219-222, (2014).

[29] Li, Z., "Sorption Kinetics of Hexadecyltrimethylammonium on Natural Clinoptilolite", Langmuir, 15: 6438-6445, (1999).

[30] Kumar, K. V., Porkodi, K. and Rocha, F., "Langmuir-Hinshelwood kinetics - A theoretical study", Catalysis Communications, 9: 82-84, (2008). 